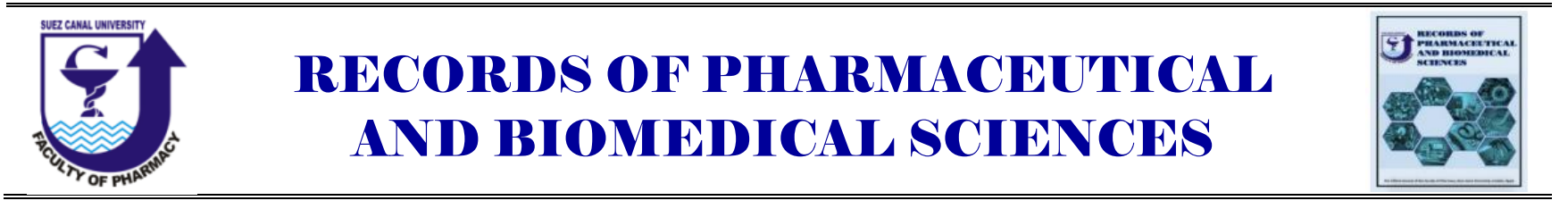

\title{
Formulation factors of starch-based nanosystems preparation and their pharmaceutical application
}

\author{
Ahmed R. Gardouh ${ }^{a, b}$, Ahmed S.G. Srag El-Din ${ }^{c^{*}}$,Yasser Mostafa ${ }^{d}$, Shadeed Gad ${ }^{a}$ \\ ${ }^{a}$ Department of Pharmaceutics and Industrial Pharmacy, Faculty of Pharmacy, Suez Canal University, \\ Ismailia, Egypt; ${ }^{b}$ Department of Pharmaceutical Sciences, Faculty of Pharmacy, Jadara University, Irbid \\ 221110, Jordan; ${ }^{\circ}$ Department of Pharmaceutics, Faculty of Pharmacy, Delta University for Science \& \\ Technology, Egypt; ${ }^{d}$ Department of Pharmacology and Toxicology, Faculty of Pharmacy, Suez Canal \\ University, Ismailia, Egypt
}

Received on: 25. 11. 2020

Revised on: 04. 12. 2020

Accepted on: 09. 12. 2020

*Correspondence Author:

Tel. : 00201008966506

E-mail address:

ahmed.shawky@deltauniv.edu.eg

\begin{abstract}
Starch-based nanosystems are considered a talented nanocarrier for drug delivery owing to their small particle size, biodegradability, and biocompatibilities. Starch-based nanosystems showed enhancement in biological activity, solubility, entrapment efficiency, and in-vitro release of several drugs. Starch-based nanosystems are categorized into two types; starch nanocrystals and starch nanoparticles. The difference between starch nanocrystals and starch nanoparticles will be summarized. Numerous techniques are employed to formulate starchbased nanosystems including chemical and physical methods. This review summarizes the existing knowledge on; a number of techniques used to formulate starch-based nanosystems, factors affecting each technique, and the advantages of combining both physical and chemical methods on the formulation time and physicochemical properties of the starch-based nanosystems. Besides, most innovative information regarding starch-based nanosystems modification on increasing entrapment efficiency will be discussed. Furthermore, applying starch-based nanosystems as effective drug delivery nanocarriers for delivering drugs and bioactive elements to improve their bioavailability will be abridged in this review.
\end{abstract}

Keywords: Starch-based nanosystems; acid hydrolysis; nanoprecipitation; ultrasound; high-pressure homogenizer

\section{Introduction}

Starch is a semi-crystalline natural polysaccharide, renewable, and biodegradable polymer created by many plants. The basic formula of this polymer is $\left(\mathrm{C}_{6} \mathrm{H}_{10} \mathrm{O}_{5}\right)$ n. It entails two glucosidic macromolecules: linear amylose (18-28\%) and branched amylopectin (72-82\%). Amylose is made up of $\alpha-1,4$ glucan units linked by glycoside bonds. Amylopectin is made of short linear $\alpha-1,4$ glucan chains which are linked by $\alpha-1,6$ glycosidic bonds. It is prearranged in crystalline clusters of double helices forming stacks of interchanging crystalline and amorphous lamellae with even repeat distance. Starch has been commonly used in 
the pharmaceutical manufacturing as a binder, disintegrate and filler in tablet formulation (Mahkam 2010, Odeku 2013, Lawal 2019, Marinopoulou, Papastergiadis et al. 2019). It is also reported that starch acted as reducing and stabilizing agents for silver nanoparticle preparation (Khan, Singh et al. 2013). Furthermore, starch was widely used to encapsulate and deliver a wide variety of food ingredients ( $\mathrm{Zhu} 2017$ ).

Recently, Starch-based nanosystems attracted focus due to their distinctive properties that are dissimilar from their bulk ingredients. Another fascinating feature of starch-based nanosystems is its capability to encapsulate various bioactive compounds, like testosterone, caffeine, ciprofloxacin, 5-fluorouracil, and curcumin. Starch-based nanosystems provide advantages of higher surface area, lower viscosity, and higher entrapment of active components (Santander-Ortega, Stauner et al. 2010, Chin, Yazid et al. 2014, Athira and Jyothi 2015, Najafi, Baghaie et al. 2016, Acevedo-Guevara, Nieto-Suaza et al. 2018, Shi, Hopfer et al. 2019). Starch-based nanosystems have been reported from different botanical sources e.g. waxy maize starch (Putaux, Molina-Boisseau et al. 2003), potato starch (Chen, Wei et al. 2008, Zheng, Ai et al. 2009, LeCorre, Vahanian et al. 2012, Shabana, Prasansha et al. 2019), cassava (García, Ribba et al. 2009, Athira and Jyothi 2015), tapioca (Hedayati, Niakousari et al. 2020), Breadfruit starch of the apyrena (Andrade, Otoni et al. 2020), Banana Starch(NietoSuaza, Acevedo-Guevara et al. 2019), wheat starch (Momenpoor, Danafar et al. 2019), Lotus seed starch(Guo, Zhao et al. 2019), corn and yam starches(Minakawa, Faria-Tischer et al. 2019).

At this review, we will discuss the two categories of starch-based nanosystems, also, different chemical and physical methods used to formulate starchbased nanosystems, and factors affecting their characters. Moreover, the starch-based nanosystems pharmaceutical application will be discussed.

\section{Starch-based nano-systems classification}

Starch-based nanosystems can be categorized according to their crystallinity into two types; starch nanocrystals (SNCs) and starch nanoparticles (SNPs). Starch nanocrystals (SNC) are crystal-like nanoparticles arising from the disorder of the semicrystalline assembly of starch granules at a temperature below their gelatinization temperature. SNCs are frequently attained through acid hydrolysis. SNCs are commonly used in the food and pharmaceutical manufacturing. It was used for emulsion stabilization (Li, Sun et al. 2012, Haaj, Thielemans et al. 2014) and as nanofillers for reinforcement of nanocomposites (González, Retegi et al. 2015, Hao, Chen et al. 2018). In contrast, SNPs are amorphous (crystallinity <10\%) spherical particles with variable sizes at the nanoscale. SNPs have been studied as a drug delivery carrier for several drugs. For instance, SNPs showed an enhancement in penetration studies on human skin when loaded with testosterone, flufenamic acid, and caffeine (Santander-Ortega, Stauner et al. 2010). Several methods were utilized to prepare SNPs including nanoprecipitation, ultrasonication, and highpressure homogenization.

Recently several studies reported that SNPs modification increases the entrapment efficiency of several drugs. Xiao et al reported that dialdehyde SNPs conjugated with 5-fluorouracil have been documented to have improved inhibition of breast cancer cells (MF-7) in vitro relative to free 5fluorouracil (Xiao, Liu et al. 2012). SNPs acetylation was found to increase $\mathrm{EE} \%$ of curcumin, ciprofloxacin (Najafi, Baghaie et al. 2016) and decrease PDI which was illuminated by the acetylation role in increasing hydrogen bonding positions in starch molecules permitting interaction with more drug molecules (Tan, Xu et al. 2009, Acevedo-Guevara, Nieto-Suaza et al. 2018).

In addition, acetylation showed an insignificant increase in PS of SNPs, which was credited to aggregation caused by intermolecular hydrogen bonding. Studies conducted by several researchers found that the acetylated SNPs allowed more controlled release than SNPs which was claimed to presence of acetyl group in their chemical structure (Acevedo-Guevara, Nieto-Suaza et al. 2018).

\section{Methods of preparation}

The methods of starch-based nanosystems are classified into either chemical methods (acid hydrolysis and nanoprecipitation) or physical methods (ultrasonication and high-pressure homogenization). Chemical methods focused on opening the starch assembly. Once the starch structure unwrapped, the formation of the hydrogen bonds can be fast-tracked, through which SNPs are formed. By comparison,, the physical methods were focused on the physical disruption of starch structure. 


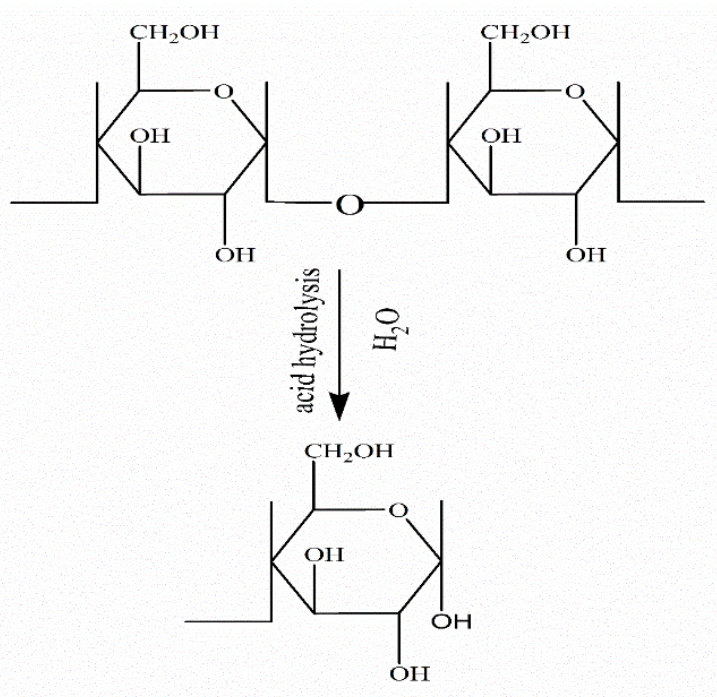

Figure 1: a schematic presentation of the acid hydrolysis mechanism.

\subsection{Acid Hydrolysis methods}

Acid hydrolysis is a simple method that has been used for SNCs preparation for many years. It involves using mild acids and temperature below temperature of the starch gelatinization. Mineral acids like Sulfuric acid and hydrochloric acid are commonly used, but recently several acids were used including citric acid (Agi, Junin et al. 2020) and organic acids like oxalic acids (Zhou, Fang et al. 2020) . Acids cause scission of the glucosidic bonds, thus altering the structure and characteristics of the native starch (Figure 1). Acids only dissolve the amorphous region while crystalline remains. The main advantage of this method is increasing the overall crystallinity and solubility of the SNCs. However, the main weaknesses of such a method remained the extended duration, along with the lowslung yield being in the range of $2-15 \%$. Extra problem also arises from the existence of a huge number of $\mathrm{OH}$ groups, which incline to reform the supra-molecular interactions that are characters of starch, yielding aggregates that limits its practical industrial utilization (Dufresne 2008).

Starch hydrolysis involves two stages, initial fast stage corresponding to hydrolysis of the amorphous part, and slow stage and corresponding to hydrolysis of the crystalline part and double helices, which is slowly eroded (LeCorre, Bras et al. 2011, Li, Yan et al. 2020, Soler, Valenzuela-Díaz et al. 2020). Two theories have been anticipated to explain the reason for the slow hydrolysis. First, the compact packaging of starch crystallites with starch chains does not permit penetration easily of $\mathrm{H}_{3} \mathrm{O}^{+1}$ into the regions. Second, acid hydrolysis of a glucosidic bond may necessitate an alteration in conformation (chair to half chair) of the Dglucopyranosyl part. This transition will be impossible if the crystalline structure halts the sugar conformation (Hoover 2000).

Several factors are affecting the characters of SNCs prepared by the acid hydrolysis process like the amylose content, concentration, and type of acid, the hydrolysis duration, and the hydrolysis temperature. The effect of acid type, hydrolysis temperature, and duration of hydrolysis on the yield, the size of SNCs, and degree of crystallinity from the different botanical origins are illustrated in Table 1.

It was first stated that the size and crystallinity of acid hydrolysis SNCs is depending on the starch botanical source (Xu, Ding et al. 2010). However, a study published by LeCorre et al (LeCorre, Bras et al. 2011) concluded that the SNCs size and crystallinity were dependent on amylose content rather than the botanical source. They scrutinized the effect of starch botanical source and amylose content on SNCs size and crystallinity. They used three botanical sources (maize, potato, and wheat) and three concentrations of maize amylose $(0,25$, and $70 \%$ ). The results of that study concluded that increasing amylose content was accompanied by a significant decrease in crystallinity of SNCs and a 
Rec. Pharm. Biomed. Sci. 5 (3), 28-39, 2021

Table 1: the effect of acid type, hydrolysis temperature, and duration of hydrolysis on the yield, the size of SNCs, and degree of crystallinity from different botanical origin 1

\begin{tabular}{|c|c|c|c|c|c|c|c|}
\hline Starch origin & Temp. & $\begin{array}{c}\text { Hydrolysis } \\
\text { duration }\end{array}$ & Acid type & Yield \% & $\begin{array}{c}\text { Particle } \\
\text { Size } \\
\end{array}$ & $\begin{array}{c}\text { Degree of } \\
\text { crystallinity }\end{array}$ & Reference \\
\hline Normal maize starch & \multirow{5}{*}{$40^{\circ} \mathrm{C}$} & \multirow{5}{*}{5 days } & \multirow{5}{*}{$3.16 \mathrm{M} \mathrm{H}_{2} \mathrm{SO}_{4}$} & - & $\begin{array}{c}47 \pm 42 \\
\mathrm{~nm}\end{array}$ & 48 & \multirow{5}{*}{$\begin{array}{c}\text { (LeCorre, } \\
\text { Bras et al. } \\
\text { 2011) }\end{array}$} \\
\hline waxy maize starch & & & & - & $\begin{array}{c}58 \pm 36 \\
\mathrm{~nm}\end{array}$ & 42 & \\
\hline Amylomaize & & & & - & $\begin{array}{c}118 \pm 53 \\
\mathrm{~nm}\end{array}$ & 35 & \\
\hline Potato starch & & & & - & $52 \pm 4 \mathrm{~nm}$ & 43 & \\
\hline Wheat starch & & & & - & $\begin{array}{c}100 \pm 50 \\
\mathrm{~nm}\end{array}$ & 35 & \\
\hline \multirow{2}{*}{ taro starch } & $40^{\circ} \mathrm{C}$ & 3 days & $\begin{array}{l}2.2 \mathrm{~N} \mathrm{HCL}^{2} \\
3.16 \mathrm{~N} \mathrm{H}_{2} \mathrm{SO}_{4}\end{array}$ & $\begin{array}{l}34.443 \\
40.592\end{array}$ & $\begin{array}{l}586,1 \mathrm{~nm} \\
395,1 \mathrm{~nm}\end{array}$ & \multirow{2}{*}{$87.3 \%$} & \multirow{4}{*}{$\begin{array}{l}\text { (Winarti, } \\
\text { Surono et } \\
\text { al. 2019) }\end{array}$} \\
\hline & $40^{\circ} \mathrm{C}$ & 5 days & $\begin{array}{c}2.2 \mathrm{~N} \mathrm{HCL} \\
3.16 \mathrm{~N} \mathrm{H}_{2} \mathrm{SO}_{4}\end{array}$ & $\begin{array}{l}30.428 \\
21.644\end{array}$ & $\begin{array}{l}695,5 \mathrm{~nm} \\
358,0 \mathrm{~nm}\end{array}$ & & \\
\hline \multirow{2}{*}{ arrowroot starch } & $40^{\circ} \mathrm{C}$ & 3 days & $\begin{array}{c}2.2 \mathrm{~N} \mathrm{HCL} \\
3.16 \mathrm{~N} \mathrm{H}_{2} \mathrm{SO}_{4}\end{array}$ & $\begin{array}{l}51.220 \\
40.010\end{array}$ & $\begin{array}{l}10,48 \mu \mathrm{m} \\
648,4 \mathrm{~nm}\end{array}$ & \multirow{2}{*}{$51.3 \%$. } & \\
\hline & $40^{\circ} \mathrm{C}$ & 5 days & $\begin{array}{c}2.2 \mathrm{~N} \mathrm{HCL} \\
3.16 \mathrm{~N} \mathrm{H}_{2} \mathrm{SO}_{4}\end{array}$ & $\begin{array}{l}38.056 \\
40.129 \\
\end{array}$ & $\begin{array}{l}938,1 \mathrm{~nm} \\
382,2 \mathrm{~nm}\end{array}$ & & \\
\hline Quinoa starch & $\begin{array}{l}30^{\circ} \mathrm{C} \\
35^{\circ} \mathrm{C} \\
40^{\circ} \mathrm{C}\end{array}$ & 5 days & $3.16 \mathrm{M} \mathrm{H}_{2} \mathrm{SO}_{4}$ & $\begin{array}{l}35.8 \\
22.8 \\
6.8\end{array}$ & $\begin{array}{c}1056.7 \\
\mathrm{~nm} \\
369.8 \mathrm{~nm} \\
243.4 \mathrm{~nm}\end{array}$ & $\begin{array}{l}34.3 \\
34.8 \\
36.2\end{array}$ & \multirow{2}{*}{$\begin{array}{c}\text { (Velásquez } \\
\text {-Castillo, } \\
\text { Leite et al. } \\
\text { 2020) }\end{array}$} \\
\hline Waxy maize starch & $40^{\circ} \mathrm{C}$ & 5 days & $3.16 \mathrm{M} \mathrm{H}_{2} \mathrm{SO}_{4}$ & 14.1 & $394.8 \mathrm{~nm}$ & 48.0 & \\
\hline waxy maize starch & $130^{\circ} \mathrm{C}$ & $15 \mathrm{~h}$ & $6 \mathrm{M}$ of oxalic acid & $89.6 \%$ & $\begin{array}{l}46.58- \\
197.15\end{array}$ & $\begin{array}{l}29.52 \%- \\
42.44 \%\end{array}$ & $\begin{array}{c}\text { (Zhou, } \\
\text { Fang et al. } \\
2020)\end{array}$ \\
\hline
\end{tabular}

mild increase in PS. It was reported in another study (Cheetham and Tao 1998) that the crystallinity of SNCs was due to double helix packing of amylopectin side chains so increasing amylose content contributes to lower the crystallinity of the SNCs. While the mild increase in PS with increasing amylose content was explained by that increasing amylose content could jam the hydrolysis pathway giving chance for particle aggregation or large particle formation. Furthermore, the study concluded that there is no correlation between botanic origin and amylose content with the SNCs shape. The type and concentration of acid were found to have a significant effect on SNCs properties. Winarti et al analyzed the influence of the form of acid and hydrolysis duration on SNCs prepared from Taro starch and Arrowroot starch.
They used $2.2 \mathrm{~N} \mathrm{HCL}$ and $3.16 \mathrm{M} \mathrm{H}_{2} \mathrm{SO}_{4}$ for hydrolysis of starch, which incubated at $40^{\circ} \mathrm{c}$ for 3 and 5 days. The SNCs obtained showed solubility improvement, a decrease in swelling power, and a decrease in temperature of gelatinization. The result of that study concluded that using HCL in hydrolysis provided a higher yield and large particle size than $\mathrm{H}_{2} \mathrm{SO}_{4}$. However, using $\mathrm{H}_{2} \mathrm{SO}_{4}$, produced a final suspension more stable than that obtained from HCL, which was attributed to the existence of sulfate group on the surface of the nanoparticles. The results also revealed that increasing $\mathrm{H}_{2} \mathrm{SO}_{4}$ hydrolysis duration decreased particle size in contrast to HCL, which increased PS by increasing hydrolysis duration. Furthermore, They claimed that the yield of SNCs had decreased due to the long time of the hydrolysis process 
consequently the extra components of starch were dissolved in the acidic medium and decrease the yield of the SNCs (Winarti, Surono et al. 2019). These data were in agreement with that reported by Li, Yan et al. who concluded that increasing hydrolysis time, decreases the molecular size and amylose content which subsequently decrease the SNCs yield (Li, Yan et al. 2020). Wang, Truong et al treated the corn starch with three concentrations of HCL $0.06,0.14$, and $1.0 \mathrm{~N}$ at $50^{\circ} \mathrm{C}$. They announced that the rate of hydrolysis and crystallinity were increased with increasing acid concentration (Wang, Truong et al. 2003).

Temperature is another factor affecting SNCs properties. A study conducted by VelásquezCastillo, Leite et al used three different hydrolysis temperatures $\left(30,35\right.$, and $\left.40^{\circ} \mathrm{C}\right)$ to study the effect of hydrolysis temperature on the yield and PS of quinoa SNCs. They claimed that rising hydrolysis temperature did not influence the crystallinity index. of quinoa SNCs, however, resulted in lowering the obtained yield, thermal stability, as well as decreasing PS of SNCs (Velásquez-Castillo, Leite et al. 2020).

In general, SNCs gained by the conventional mineral acid hydrolysis technique are restricted because of long time required and low yield obtained. This tendency hinders the industrial application of SNCs. For the aforementioned reasons, several procedures with physical treatments or a combination of different methods were attempt. It was conveyed that the waxy maize SNCs properties were improved after dialdehyde modification. The waxy maize SNCs modified with dialdehyde showed Higher stability and more water dispersibility compared with waxy maize SNCs prepared without dialdehyde modification (Chen, Hao et al. 2019). In addition, enzymatic pretreatment was innovated to minimise the acidic hydrolysis period and increase the yield of SNCs of waxy maize; the final yield of SNCs of waxy maize obtained was $15 \%$ (LeCorre, Vahanian et al. 2012). To expand the SNCs yield, Kim, Han et al prepared waxy maize SNCs with a high yield of $78 \%$ using ultrasonication after cold sulfuric acid hydrolysis for 6 days (Kim, Han et al. 2013). Recently, Shabana et al (Shabana, Prasansha et al. 2019) reported that the combination of ultrasonication and acid hydrolysis allows the development of smaller particles and increased the antioxidant loading capacity. Zhou, Fang et al. prepared waxy maize SNCs using dry-heated oxalic acid hydrolysis. They obtained a high yield of SNCs $(89.6 \%)$ with PS ranged from 46.58 to $197.15 \mathrm{~nm}$, and the PDI was
0.28-0.52 (Zhou, Fang et al. 2020).

\subsection{Nanoprecipitation method}

Nanoprecipitation, also defined as the solvent displacement method, which involves two solvent systems that are miscible with each other. Nanoprecipitation is a simple method that not requires specialized equipment or complex operating conditions (Chong, Chin et al. 2020, Gutiérrez, Morán et al. 2020, Liu, Yang et al. 2020). It has been extensively used in pharmaceutical industry to prepare SNPs (Joye and McClements 2013). It involves the slow addition of a dilute polymer solution to a non-solvent or sequential addition of non-solvent into the polymer solution, which leads to the formation of nanoscale polymer particles (Acevedo-Guevara, NietoSuaza et al. 2018). The process is primarily based on the interfacial biopolymers deposition and displacement of water miscible semi-polar solvent from a lipophilic solution. Qin et al prepared SNPs from different botanical sources including; corn, tapioca, sweet potato, potato, and pea starch by dropwise addition of ethanol into a dilute solution of gelatinized starch under stirring. They reported that the PS of SNPs was between 30-75 nm(Qin, Liu et al. 2016). The properties of SNPs can be controlled by several factors including; starch concentration, the addition of surfactants, and the ratio of starch solution to non-solvent used in the precipitation. The effect of these factors on PS and morphology of SNPs are illustrated in Table 2.

Starch concentration was found to have a great role in determining the PS and encapsulation efficiency of the SNPs. An rise in the concentration of waxy maize starch acetate has been recorded from 1 to 20 $\mathrm{mg} / \mathrm{ml}$ resulted in increasing the PS from 249 to $720 \mathrm{~nm}$ (Tan, $\mathrm{Xu}$ et al. 2009). Also, an increase in corn starch concentration was reported to increase the PS of SNPs from 132 to $220 \mathrm{~nm}$ (Hebeish, ElRafie et al. 2014). Similar findings were reported by Hedayati and nikaousari et al whom used tapioca starch (Hedayati, Niakousari et al. 2020). The reported increase in the PS with increasing starch concentration arises from the higher viscosity and aggregation obtained that lead to the formation of a large diameter. It is also reported by $\mathrm{Fu}$ et al that increasing starch concentration decreased the lutein content. However, encapsulating lutein into SNPs increased lutein stability against chemical oxidation and enhanced its water dispersity (Fu, Yang et al. 2019). 
Rec. Pharm. Biomed. Sci. 5 (3), 28-39, 2021

Table 2: The effect of the ratio of starch solution to non-solvent used in the precipitation on particle size and morphology of starch nanoparticles

\begin{tabular}{|c|c|c|c|c|c|c|}
\hline $\begin{array}{c}\text { Starch } \\
\text { origin }\end{array}$ & $\begin{array}{c}\text { Starch } \\
\text { concentration }\end{array}$ & $\begin{array}{l}\text { Solvent } \\
\text { system }\end{array}$ & $\begin{array}{c}\text { Starch } \\
\text { solution: } \\
\text { non solvent }\end{array}$ & PS & Morphology & ref \\
\hline $\begin{array}{l}\text { Debranched } \\
\text { waxy corn } \\
\text { starch }\end{array}$ & $10 \mathrm{mg} / \mathrm{ml}$ & $\begin{array}{l}\text { Water: } \\
\text { ethanol }\end{array}$ & $\begin{array}{l}1: 3 \\
1: 4 \\
1: 5\end{array}$ & $\begin{array}{l}80-170 \\
20-100 \\
50-140\end{array}$ & $\begin{array}{l}\text { Spherical } \\
\text { Spherical } \\
\text { Spherical }\end{array}$ & $\begin{array}{l}\text { (Qiu, Yang et } \\
\text { al. 2016) }\end{array}$ \\
\hline $\begin{array}{l}\text { Amylose } \\
\text { Potato starch }\end{array}$ & $10 \mathrm{mg} / \mathrm{ml}$ & $\begin{array}{l}\text { Water: } \\
\text { ethanol }\end{array}$ & $\begin{array}{l}1: 3 \\
1: 4 \\
1: 5\end{array}$ & $\begin{array}{c}100-200 \\
30-60 \\
70-100\end{array}$ & $\begin{array}{l}\text { Spherical } \\
\text { Spherical } \\
\text { Spherical }\end{array}$ & $\begin{array}{l}\text { (Qiu, Qin et } \\
\text { al. 2016) }\end{array}$ \\
\hline $\begin{array}{l}\text { Normal corn } \\
\text { starch }\end{array}$ & $10 \mathrm{mg} / \mathrm{ml}$ & $\begin{array}{l}\text { Dimethyl- } \\
\text { sulfoxide }\end{array}$ & $\begin{array}{c}1: 5 \\
1: 10 \\
1: 20 \\
1: 30 \\
\end{array}$ & $\begin{array}{l}208.1- \\
213.1\end{array}$ & $\begin{array}{c}\text { not clear } \\
\text { not clear } \\
\text { irregular spherical } \\
\text { irregular spherical }\end{array}$ & $\begin{array}{l}\text { (Wu, Chang et } \\
\text { al. 2016) }\end{array}$ \\
\hline $\begin{array}{l}\text { native sago } \\
\text { starch }\end{array}$ & $10 \mathrm{mg} / \mathrm{ml}$ & $\begin{array}{c}\text { NaOH/urea } \\
\text { (NU) (0.8:1 } \\
\text { wt } \%)\end{array}$ & $\begin{array}{l}1: 10 \\
1: 15 \\
1: 20 \\
\end{array}$ & $300-400$ & $\begin{array}{c}\text { fibrous } \\
\text { mixture of spherical } \\
\text { and elongated fiber } \\
\text { spherical }\end{array}$ & $\begin{array}{l}\text { (Chin, Pang et } \\
\text { al. 2011) }\end{array}$ \\
\hline
\end{tabular}

The presence of surfactant during the nanoprecipitation process was found to have a significant effect on decreasing the PS of SNPs. Chin and Pang et al synthesized SNPs between 300 $\mathrm{nm}$ and $400 \mathrm{~nm}$ by controlled drop-wise precipitation of $1 \mathrm{ml} 1 \%$ native sago starch solution to excess absolute alcohol $(10 \mathrm{~mL}, 15 \mathrm{~mL}$, and 20 $\mathrm{mL}$ ). in contrast, when they used $4 \%$ tween 80 as a Surfactants during precipitation they obtained SNPs with a mean diameter of about $150 \mathrm{~nm}$ (Chin, Pang et al. 2011). Putro and ismadji et al studied the effect of ionic surfactant (Cetyl trimethylammonium bromide and Sodium dodecyl sulfate) and non-ionic surfactant (Tween 20) on the crystalline structure of SNPs prepared from potato starch. They reported that surfactants increase the crystallinity of SNPs, which was contributed to the ability of surfactants to penetrate the starch internal cavity of the single helix part. The study concluded that the ionic surfactant gave higher drug uptake than the non-ionic surfactant, which was explained by ionic surfactant charges that increase the affinity of surfactant molecules toward starch particles (Putro, Ismadji et al. 2020). It is believed that the existance of surfactants during the precipitation process limits the aggregation of the SNPs and hence reduces their PS. (Chin, Pang et al. 2011). The ratios of starch solution to non-solvent used were reported to have a significant impact on the PS and morphology of SNPs. Qiu et al investigated the effect of starch solution to the ethanol ratio on the PS of potato amylose SNPs. They prepared spherical amylose SNPs by dropwise adding a fixed quantity of absolute ethanol $(30,40,50 \mathrm{~mL})$ into $10 \mathrm{ml}$ gelatinized amylose solution $(1 \% \mathrm{~W} / \mathrm{V})$. The PS of SNPs decreased as ethanol amount increased from 30 to $40 \mathrm{ml}$ then the PS was slightly increased when the amount of ethanol increased from 40 to $50 \mathrm{ml}$ (Qiu, Qin et al. 2016). Similar findings have been documented by Qiu, Yang et al. (Qiu, Yang et al. 2016) who prepared SNPs by adding the same quantities of ethanol $(30,40,50$ $\mathrm{mL}$ ) into $10 \mathrm{ml}$ of short linear glucan solution $(1 \% \mathrm{~W} / \mathrm{V})$ obtained from debranched waxy corn starch. The stated increase in PS was due to the decrease in the solvent power of starch solution and nucleation induced by increasing ethanol amount. Also, could be due to collision among particles leads to aggregation (Joye and McClements 2013, Qiu, Qin et al. 2016). There is a linear dependence between PS and the polarity of the mixture. It was found that the PS decreased as the solubility of the solvent mixture decreased (Tan, Xu et al. 2009, Qiu, Yang et al. 2016, Wu, Chang et al. 2016). Regarding the effect of the ratio of starch solution to non-solvent used on the morphology of SNPs. 
Chin, Pang, et al prepared SNPs by addition of $1 \mathrm{ml}$ of sago starch solution $(10 \mathrm{mg} / \mathrm{ml})$ into different volumes of absolute ethanol $(10,15$, and $20 \mathrm{ml})$ at a constant stirring rate. The findings of that analysis concluded that the morphology of the SNPs was dependent on the volume of ethanol used in precipitation. SNPs fibrous in shape were obtained when the ethanol volume was $10 \mathrm{ml}$. A mixture of spherical and elongated fiber-like SNPs was reported at a volume of $15 \mathrm{ml}$. However, when the ethanol volume ratio was $20 \mathrm{ml}$, spherical-shaped SNPs with PS between 300 and $400 \mathrm{~nm}$ were obtained (Chin, Pang et al. 2011). In Another study conducted by Wu.et al, an increase in the ethanol from 5 to $30 \mathrm{ml}$ at precipitation of $1 \mathrm{ml}$ of corn starch-dimethylsulfoxide solution $(10 \mathrm{mg} / \mathrm{ml})$ has been significantly changed the morphology of the SNPs. At 5 and $10 \mathrm{ml}$ volume of ethanol, the shape of SNPs was not clear because of the aggregation. An irregular spherical shape with distinct surface SNPs was observed at ethanol volume $20 \mathrm{ml}$ and a further increase in ethanol volume to $30 \mathrm{ml}$ did not show any changes in the particle size and morphology of SNPs (Wu, Chang et al. 2016).

Recently it was reported that the combination of nanoprecipitation and another method or chemicals will faster the process. El-sheikh et al synthesized SNPs based on blending $\mathrm{NaOH}$ and glycerol in an aqueous solution during the synthesis progression while the precipitation of the SNPs is performed using ethanol under homogenization at ambient environment. The obtained nanoparticles were reported to be round in shape and uniformly distributed with a size of about $62.5 \mathrm{~nm}$. The FT-IR findings revealed that the strength of the SNPs OH stretching band was higher than that of the native starch; this was due to the power of sodium hydroxide gelatinization and to the effect of homogenization throughout precipitation on damaging the crystalline structure of the starch molecules. The X-ray result confirmed the amorphous structure which was due to the swelling effect of sodium hydroxide on the starch and using high pressure homogenization (El-Sheikh 2017). Despite the nanoprecipitation advantages, it requires high levels of non-solvents such as isopropanol, ethanol, and acetone, which hinder its industrial application.

\subsection{Ultrasound technique}

The ultrasound technique is an eco-friendly method for the physical disruption of starch structure. It splits the covalent bonds in polymeric material through mechanical effects associated with the collapse of micro bubbles by sound waves. Exposing the starch solution to ultrasonic waves results in a reduction of the molar mass and provides more channels for water dispersion through the starch granules. Izidoro et al explored the effect of ultrasound on the physical properties of starch suspensions. The outcome of this investigation revealed an improvement in starch solubility and water absorption ability after ultrasound treatment at a frequency of $20 \mathrm{kHz}$. (24 $\mathrm{W}$ power with $40 \%$ amplitude) for $1 \mathrm{~h}$ (Izidoro, Sierakowski et al. 2011).

It was reported that the ultra-sonication is affected by the temperature of the preparation. Zhu et al. reported that ultrasonic treatment of starch suspension for $30 \mathrm{~min}$ at temperatures ranging from 20 to $30^{\circ} \mathrm{C}$ resulted in a reduction of the molecular order in crystalline lamellae affecting the supramolecular structure of starch without any reduction in particle size (Zhu, Li et al. 2012). In contrast, at a temperature around $5^{\circ} \mathrm{C}$, the ultrasound treatment for the same time resulted in damage to the surface of the starch granules (Zuo, Hébraud et al. 2012). The ultra-sonication treatment was reported to decrease the crystallinity and degradation temperature of the starch producing SNPs with amorphous characters. Andrade et al prepared SNPs by submitting a $0.5 \%(\mathrm{w} / \mathrm{v})$ breadfruit starch suspension to $75 \mathrm{~min}$ of ultra-sonication (a frequency of $20 \mathrm{kHz}$ using a $50-\mathrm{W}$ probe ultrasonic processor) at a temperature between 8 and $10{ }^{\circ} \mathrm{C}$. The SNPs obtained were $145 \mathrm{~nm}$ in diameter and had a low zeta potential $(-17 \mathrm{mv})$ which did not prevent SNPs aggregation. The $\mathrm{x}$-ray results revealed a break of the crystalline assembly of native starch, and thus SNPs with amorphous characters obtained. The thermal analysis result indicated that the native starch had a degradation temperature higher than SNPs (Andrade, Otoni et al. 2020).

Several studies reported that the crystallinity of SNPs not only depends on the ultra-sonication but also depends on the source of starch and the ratio between amylose and amylopectin present in the starch (Bel Haaj, Magnin et al. 2013, Minakawa, Faria-Tischer et al. 2019). Minakawa et al, prepared starch nanoparticles from three different types of starch (cassava, corn, and yam) differ in amylose content. They subjected a solution of $10 \%$ starch for 30 minutes sonication at $25^{\circ} \mathrm{C}$ and the yield for all starch used was $12 \pm 1 \%$ starch nanoparticles. The reported results revealed that starch with high amylose content produced particles with smaller size and low crystallinity 
while starch with low amylose content produces large particles size and amorphous particles. The results also revealed a decrease in crystallinity and thermal stability of nanoparticles compared with native starch from different sources which was attributed to the effect of ultra-sonication on decreasing polymerization and increase number of $\mathrm{OH}$ groups on the surface of nanoparticles (Minakawa, Faria-Tischer et al. 2019). Bel Haaj et al. prepared SNPs from standard starch $(70 \%$ amylopectin) and waxy maize (99\% amylopectin) by 75-minute sonication at $80 \%$ output at temperature ranged from 8 to $10^{\circ} \mathrm{C}$. The results revealed that the particle size was sharply decreased at the first 30 minutes and 45 minutes for the waxy starch and the standard starch respectively then continued to decrease more slowly. The nanoparticles obtained from the waxy maize were less aggregated than those obtained from standard starch were. It was observed that SNPs obtained from waxy maize had lower crystallinity than those obtained from the standard starch. (Bel Haaj, Magnin et al. 2013).

It was reported that the combination of ultrasonication and chemical process produced nanoparticles with more desired properties. Shabana et al studied the effect of combining ultra-sonication and acid hydrolysis on SNPs preparation. They prepared starch nanoparticles by sonication, sonication assisted with acid hydrolysis, and conventional acid hydrolysis method. Diluted sulfuric acid was used in the hydrolysis process and the temperature was maintained at $10^{\circ} \mathrm{C}$ during the experiment. The reported result of PS analysis showed that the PS decreased with increasing sonication time and particles obtained from ultrasound-assisted acid treatment were the smallest one $(40 \mathrm{~nm})$ compared to that obtained from ultrasonication only $(80 \mathrm{~nm})$ and conventional acid hydrolysis method $(1596 \mathrm{~nm})$. The molecular weight of starch was decreased in ultrasoundassisted acid treatment more than ultrasound, which was attributed to increasing molecules structural breakdown by using sulfuric acid. Despite the role of acid in increasing the crystallinity of SNPs, it was found that acid treatment has not increased the crystalline pattern of nanoparticles, which was attributed to the modification of amylose to amylopectin associated with acid treatment (Shabana, Prasansha et al. 2019).

The effect of acid hydrolysis on the crystallinity of SNPs that was prepared by ultra-sonication was studied twice by Kim et al. in different conditions.
The results of the two studies concluded that ultrasonication during the acid hydrolysis process was coupled with an increase in crystallinity (Kim, Han et al. 2013). In contrast, when ultra-sonication was performed after the acid hydrolysis at $4{ }^{\circ} \mathrm{C}$ the crystalline pattern was decreased (Kim, Park et al. 2013).

Mudasir et al produced SNPs from different starch sources by mild alkali hydrolysis and ultrasonication. The nanoparticles obtained were ranged from 402 to $606 \mathrm{~nm}$ in diameter. The difference in particle size was attributed to the difference in the branching pattern of amylopectin within the starch. The study also revealed a notable increase in water absorption capacity and loss of crystallinity of all the prepared SNPs (Mudasir, Adil et al. 2020).

\subsection{High-Pressure Homogenization}

High-pressure homogenization is another physical and eco-friendly technique used for SNPs preparation. It involves passing the starch slurry through a high-pressure homogenizer under a certain pressure to decrease PS from micro to Nano size. A $5 \%$ starch slurry was passed through the chambers of a Microfluidizer at a rate of 133 $\mathrm{ml} / \mathrm{min}$ under the persistent pressure of $207 \mathrm{MPa}$ several times. The starch PS was reduced from 3-6 $\mu \mathrm{m}$ to $10-20 \mathrm{~nm}$ without any change in crystal structure or thermal stability of starch granules (Liu, Wu et al. 2009). Liu et al. reported the use of a high-pressure homogenization method to prepare corn SNPs with a yield of almost $100 \%$. However, the high yield gained, the method does not allow appropriate control of PS (Liu, Wu et al. 2009). Sodium trimetaphosphate cross-linked SNPs were produced by combining a high-pressure homogenization technique with mini-emulsion cross-linking method (Shi, Li et al. 2011). However, the efficiency of the technique, its use is limited owing to low yield obtained as only low concentration starch slurry can be processed for homogenization.

\section{Starch-based pharmaceutical application}

Recently, Starch-based Nanosystems are talented as nanocarriers of different bioactive molecules for different routes. It was reported that starch-based Nanosystem was successfully used as a bioactive carrier for several drugs including; Diclofenac sodium (El-Naggar, El-Rafie et al. 2015),curcumin (Acevedo-Guevara, Nieto-Suaza et al. 2018), two antioxidant: gallic acid and butylated 
hydroxytoluene (de Oliveira, Fornaciari et al. 2018), Doxorubicin $\mathrm{HCl}$ (Yang, Li et al. 2017), Catechin (Ahmad, Mudgil et al. 2019), Ascorbic Acid and Oxalic Acid (Shabana, Prasansha et al. 2019), 5fluorouracil (Norul Nazilah, Nagarjun Konduru et al. 2018), Vitamin D3 (Hasanvand, Fathi et al. 2018), and Quercetin(Farrag, Ide et al. 2018)

Ismail and Gopinath enhanced antibacterial activity and decreased resistance complication of penicillin and streptomycin against streptococcus pyogenes by loading on SNPs. They prepared SNPs using nanoprecipitation method, which produced spherical nanoparticles with uniform size distribution. The reported result showed a significant increase in the inhibition zone of antibiotic-loaded SNPs than antibiotics alone (Ismail and Gopinath 2017). Jong, Ju, and Zhang prepared SNPs loaded with doxorubicin, they reported that the SNPs protected the doxorubicin in the acidic conditions and showed good in-vitro drug release under neutral conditions (Jong, Ju et al. 2017).

\section{References}

Acevedo-Guevara, L., L. Nieto-Suaza, L. T. Sanchez, M. I. Pinzon and C. C. Villa (2018). "Development of native and modified banana starch nanoparticles as vehicles for curcumin." International journal of biological macromolecules 111: 498-504.

Agi, A., R. Junin, A. Arsad, A. Abbas, A. Gbadamosi, N. B. Azli and J. Oseh (2020). "Ultrasound-assisted weak-acid hydrolysis of crystalline starch nanoparticles for chemical enhanced oil recovery." International journal of biological macromolecules 148: 1251-1271.

Ahmad, M., P. Mudgil, A. Gani, F. Hamed, F. A. Masoodi and S. Maqsood (2019). "Nanoencapsulation of catechin in starch nanoparticles: Characterization, release behavior and bioactivity retention during simulated in-vitro digestion." Food Chemistry 270: 95-104.

Andrade, I. H., C. G. Otoni, T. S. Amorim, G. P. Camilloto and R. S. Cruz (2020). "Ultrasoundassisted extraction of starch nanoparticles from breadfruit (Artocarpus altilis (Parkinson) Fosberg)." Colloids and Surfaces A: Physicochemical and Engineering Aspects 586: 124277.

Athira, G. K. and A. N. Jyothi (2015). "Cassava starch-poly (vinyl alcohol) nanocomposites for the controlled delivery of curcumin in cancer prevention and treatment." Starch-Stärke 67(5-6): 549-558.

Bel Haaj, S., A. Magnin, C. Pétrier and S. Boufi (2013). "Starch nanoparticles formation via high power ultrasonication." Carbohydrate Polymers 92(2): 1625-1632.

Cheetham, N. W. and L. Tao (1998). "Variation in crystalline type with amylose content in maize starch granules: an X-ray powder diffraction study." Carbohydrate polymers 36(4): 277-284.

Chen, G., M. Wei, J. Chen, J. Huang, A. Dufresne and P. R. Chang (2008). "Simultaneous reinforcing and toughening: new nanocomposites of waterborne polyurethane filled with low loading level of starch nanocrystals." Polymer 49(7): 18601870.

Chen, Y., Y. Hao, K. Ting, Q. Li and Q. Gao (2019). "Preparation and emulsification properties of dialdehyde starch nanoparticles." Food Chemistry 286: 467-474.

Chin, S. F., S. C. Pang and S. H. Tay (2011). "Size controlled synthesis of starch nanoparticles by a simple nanoprecipitation method." Carbohydrate Polymers 86(4): 1817-1819.

Chin, S. F., M. Yazid, S. N. Akmar and S. C. Pang (2014). "Preparation and characterization of starch nanoparticles for controlled release of curcumin." International Journal of Polymer Science 2014.

Chong, W.-H., S.-F. Chin, S.-C. Pang and K.-Y. Kok (2020). "Synthesis and Characterisation of Piperine-loaded Starch Nanoparticles." Journal of Physical Science 31(1): 57-68.

de Oliveira, N. R., B. Fornaciari, S. Mali and G. M. Carvalho (2018). "Acetylated Starch-Based Nanoparticles: Synthesis, Characterization, and Studies of Interaction With Antioxidants." Starch Stärke 70(3-4): 1700170.

Dufresne, A. (2008). Cellulose-based composites and nanocomposites. Monomers, polymers and composites from renewable resources, Elsevier: 401-418.

El-Naggar, M. E., M. El-Rafie, M. El-Sheikh, G. S. El-Feky and A. Hebeish (2015). "Synthesis, characterization, release kinetics and toxicity profile of drug-loaded starch nanoparticles." International journal of biological macromolecules 81: 718-729.

El-Sheikh, M. A. (2017). "New technique in starch nanoparticles synthesis." Carbohydrate Polymers 176: $214-219$.

Farrag, Y., W. Ide, B. Montero, M. Rico, S. Rodríguez-Llamazares, L. Barral and R. Bouza (2018). "Preparation of starch nanoparticles loaded with quercetin using nanoprecipitation technique." 
International Journal of Biological Macromolecules 114: 426-433.

$\mathrm{Fu}$, Y., J. Yang, L. Jiang, L. Ren and J. Zhou (2019). "Encapsulation of Lutein into Starch Nanoparticles to Improve Its Dispersity in Water and Enhance Stability of Chemical Oxidation." Starch-Stärke 71(5-6): 1800248.

García, N. L., L. Ribba, A. Dufresne, M. I. Aranguren and S. Goyanes (2009). "Physicomechanical properties of biodegradable starch nanocomposites." Macromolecular Materials and Engineering 294(3): 169-177.

González, K., A. Retegi, A. González, A. Eceiza and N. Gabilondo (2015). "Starch and cellulose nanocrystals together into thermoplastic starch bionanocomposites." Carbohydrate Polymers 117: 83-90.

Guo, Z., B. Zhao, L. Chen and B. Zheng (2019). "Physicochemical Properties and Digestion of Lotus Seed Starch under High-Pressure Homogenization." Nutrients 11(2): 371.

Gutiérrez, G., D. Morán, A. Marefati, J. Purhagen, M. Rayner and M. Matos (2020). "Synthesis of controlled size starch nanoparticles (SNPs)." Carbohydrate Polymers 250: 116938.

Haaj, S. B., W. Thielemans, A. Magnin and S. Boufi (2014). "Starch nanocrystal stabilized pickering emulsion polymerization for nanocomposites with improved performance." ACS Applied Materials \& Interfaces 6(11): 8263-8273.

Hao, Y., Y. Chen, Q. Li and Q. Gao (2018). "Preparation of starch nanocrystals through enzymatic pretreatment from waxy potato starch." Carbohydrate polymers 184: 171-177.

Hasanvand, E., M. Fathi and A. Bassiri (2018). "Production and characterization of vitamin D 3 loaded starch nanoparticles: effect of amylose to amylopectin ratio and sonication parameters." Journal of food science and technology 55(4): 13141324.

Hebeish, A., M. El-Rafie, M. El-Sheikh and M. E. El-Naggar (2014). "Ultra-fine characteristics of starch nanoparticles prepared using native starch with and without surfactant." Journal of Inorganic and Organometallic Polymers and Materials 24(3): 515-524.

Hedayati, S., M. Niakousari and Z. Mohsenpour (2020). "Production of tapioca starch nanoparticles by nanoprecipitation-sonication treatment." International Journal of Biological Macromolecules 143: 136-142.

Hoover, R. (2000). "Acid-treated starches." Food Reviews International 16(3): 369-392.

Ismail, N. S. and S. C. Gopinath (2017). "Enhanced antibacterial effect by antibiotic loaded starch nanoparticle." Journal of the Association of Arab Universities for Basic and Applied Sciences 24(1): 136-140.

Izidoro, D. R., M.-R. Sierakowski, C. W. I. Haminiuk, C. F. De Souza and A. de Paula Scheer (2011). "Physical and chemical properties of ultrasonically, spray-dried green banana (Musa cavendish) starch." Journal of food engineering 104(4): 639-648.

Jong, K., B. Ju and S. Zhang (2017). "Synthesis of pH-responsive N-acetyl-cysteine modified starch derivatives for oral delivery." Journal of Biomaterials science, Polymer edition 28(14): 1525-1537.

Joye, I. J. and D. J. McClements (2013). "Production of nanoparticles by anti-solvent precipitation for use in food systems." Trends in Food Science \& Technology 34(2): 109-123.

Khan, Z., T. Singh, J. I. Hussain, A. Y. Obaid, S. A. AL-Thabaiti and E. El-Mossalamy (2013). "Starch-directed green synthesis, characterization and morphology of silver nanoparticles." Colloids and Surfaces B: Biointerfaces 102: 578-584.

Kim, H.-Y., J.-A. Han, D.-K. Kweon, J.-D. Park and S.-T. Lim (2013). "Effect of ultrasonic treatments on nanoparticle preparation of acidhydrolyzed waxy maize starch." Carbohydrate polymers 93(2): 582-588.

Kim, H.-Y., D. J. Park, J.-Y. Kim and S.-T. Lim (2013). "Preparation of crystalline starch nanoparticles using cold acid hydrolysis and ultrasonication." Carbohydrate Polymers 98(1): 295-301.

Lawal, M. V. (2019). "Modified starches as direct compression excipients-Effect of physical and chemical modifications on tablet properties: A review." Starch-Stärke 71(1-2): 1800040.

LeCorre, D., J. Bras and A. Dufresne (2011). "Evidence of micro-and nanoscaled particles during starch nanocrystals preparation and their isolation." Biomacromolecules 12(8): 3039-3046.

LeCorre, D., J. Bras and A. Dufresne (2011). "Influence of botanic origin and amylose content on the morphology of starch nanocrystals." Journal of Nanoparticle Research 13(12): 7193-7208.

LeCorre, D. b., E. Vahanian, A. Dufresne and J. Bras (2012). "Enzymatic pretreatment for preparing starch nanocrystals." Biomacromolecules 13(1): 132-137. 
Li, C., P. Sun and C. Yang (2012). "Emulsion stabilized by starch nanocrystals." Starch-Stärke 64(6): 497-502.

Li, H., S. Yan, H. Mao, J. Ji, M. Xu, S. Zhang, J. Wang, Y. Liu and B. Sun (2020). "Insights into maize starch degradation by sulfuric acid from molecular structure changes." Carbohydrate Polymers 229: 115542.

Liu, D., Q. Wu, H. Chen and P. R. Chang (2009). "Transitional properties of starch colloid with particle size reduction from micro-to nanometer." Journal of Colloid and Interface Science 339(1): 117-124.

Liu, Y., G. Yang, T. Baby, D. Chen, D. A. Weitz and C. X. Zhao (2020). "Stable polymer nanoparticles with exceptionally high drug loading by sequential nanoprecipitation." Angewandte Chemie International Edition 59(12): 4720-4728.

Mahkam, M. (2010). "Starch-based polymeric carriers for oral-insulin delivery." Journal of Biomedical Materials Research Part A: An Official Journal of The Society for Biomaterials, The Japanese Society for Biomaterials, and The Australian Society for Biomaterials and the Korean Society for Biomaterials 92(4): 1392-1397.

Marinopoulou, A., E. Papastergiadis and S. N. Raphaelides (2019). "Inclusion complexes of nongranular maize starch with fatty acids and ibuprofen. A comparative study of their morphology and structure." Starch-Stärke 71(1-2): 1800100.

Minakawa, A. F. K., P. C. S. Faria-Tischer and S. Mali (2019). "Simple ultrasound method to obtain starch micro- and nanoparticles from cassava, corn and yam starches." Food Chemistry 283: 11-18.

Momenpoor, B., F. Danafar and F. Bakhtiari (2019). Size Controlled Preparation of Starch Nanoparticles from Wheat Through Precipitation at Low Temperature. Journal of Nano Research, Trans Tech Publ.

Mudasir, A., G. Adil, H. Ifra, Q. Huang and S. Hassan (2020). "Production and characterization of starch nanoparticles by mild alkali hydrolysis and ultra-sonication process." Scientific Reports (Nature Publisher Group) 10(1).

Najafi, S. H. M., M. Baghaie and A. Ashori (2016). "Preparation and characterization of acetylated starch nanoparticles as drug carrier: Ciprofloxacin as a model." International journal of biological macromolecules 87: 48-54.

Nieto-Suaza, L., L. Acevedo-Guevara, L. T. Sánchez, M. I. Pinzón and C. C. Villa (2019). "Characterization of Aloe vera-banana starch composite films reinforced with curcumin-loaded starch nanoparticles." Food Structure 22: 100131.

Norul Nazilah, A. 1., V. Nagarjun Konduru and W. Tin Wui (2018). "Development of resistant corn starch for use as an oral colon-specific nanoparticulate drug carrier." Pure and Applied Chemistry 90(6): 1073-1084.

Odeku, O. A. (2013). "Potentials of tropical starches as pharmaceutical excipients: A review." Starch-Stärke 65(1-2): 89-106.

Putaux, J.-L., S. Molina-Boisseau, T. Momaur and A. Dufresne (2003). "Platelet nanocrystals resulting from the disruption of waxy maize starch granules by acid hydrolysis." Biomacromolecules 4(5): 1198-1202.

Putro, J. N., S. Ismadji, C. Gunarto, F. E. Soetaredjo and Y. H. Ju (2020). "A study of anionic, cationic, and nonionic surfactants modified starch nanoparticles for hydrophobic drug loading and release." Journal of Molecular Liquids 298: 112034.

Qin, Y., C. Liu, S. Jiang, L. Xiong and Q. Sun (2016). "Characterization of starch nanoparticles prepared by nanoprecipitation: Influence of amylose content and starch type." Industrial Crops and Products 87: 182-190.

Qiu, C., Y. Qin, S. Zhang, L. Xiong and Q. Sun (2016). "A comparative study of size-controlled worm-like amylopectin nanoparticles and spherical amylose nanoparticles: Their characteristics and the adsorption properties of polyphenols." Food chemistry 213: 579-587.

Qiu, C., J. Yang, S. Ge, R. Chang, L. Xiong and Q. Sun (2016). "Preparation and characterization of size-controlled starch nanoparticles based on short linear chains from debranched waxy corn starch." LWT 74: 303-310.

Santander-Ortega, M., T. Stauner, B. Loretz, J. L. Ortega-Vinuesa, D. Bastos-González, G. Wenz, U. F. Schaefer and C.-M. Lehr (2010). "Nanoparticles made from novel starch derivatives for transdermal drug delivery." Journal of controlled release 141(1): 85-92.

Shabana, S., R. Prasansha, I. Kalinina, I. Potoroko, U. Bagale and S. Shirish (2019). "Ultrasound assisted acid hydrolyzed structure modification and loading of antioxidants on potato starch nanoparticles." Ultrasonics sonochemistry 51: 444450.

Shi, A.-m., D. Li, L.-j. Wang, B.-z. Li and B. 
Adhikari (2011). "Preparation of starch-based nanoparticles through high-pressure homogenization and miniemulsion cross-linking: Influence of various process parameters on particle size and stability." Carbohydrate Polymers 83(4): 1604-1610.

Shi, L., H. Hopfer, G. R. Ziegler and L. Kong (2019). "Starch-menthol inclusion complex: Structure and release kinetics." Food Hydrocolloids 97: 105183.

Soler, A., E. D. Valenzuela-Díaz, G. Velazquez, J. A. Huerta-Ruelas, E. Morales-Sanchez, R. Hernandez-Gama and G. Mendez-Montealvo (2020). "Double helical order and functional properties of acid-hydrolyzed maize starches with different amylose content." Carbohydrate Research 490: 107956.

Tan, Y., K. Xu, L. Li, C. Liu, C. Song and P. Wang (2009). "Fabrication of size-controlled starch-based nanospheres by nanoprecipitation." ACS applied materials \& interfaces 1(4): 956-959.

Velásquez-Castillo, L. E., M. A. Leite, C. Ditchfield, P. J. do Amaral Sobral and I. C. F. Moraes (2020). "Quinoa starch nanocrystals production by acid hydrolysis: Kinetics and properties." International Journal of Biological Macromolecules 143: 93-101.

Wang, Y.-J., V.-D. Truong and L. Wang (2003). "Structures and rheological properties of corn starch as affected by acid hydrolysis." Carbohydrate Polymers 52(3): 327-333.

Winarti, C., I. Surono and M. Uswah (2019). Effect of Acid And Hydrolysis Duration on The Characteristics of Arrowroot and Taro Starch Nanoparticles. IOP Conference Series: Earth and Environmental Science, IOP Publishing.

Wu, X., Y. Chang, Y. Fu, L. Ren, J. Tong and J. Zhou (2016). "Effects of non-solvent and starch solution on formation of starch nanoparticles by nanoprecipitation." Starch-Stärke 68(3-4): 258-263.
Xiao, S., X. Liu, C. Tong, L. Zhao, X. Liu, A. Zhou and Y. Cao (2012). "Dialdehyde starch nanoparticles as antitumor drug delivery system: An in vitro, in vivo, and immunohistological evaluation." Chinese science bulletin 57(24): 32263232.

Xu, Y., W. Ding, J. Liu, Y. Li, J. F. Kennedy, Q. $\mathrm{Gu}$ and S. Shao (2010). "Preparation and characterization of organic-soluble acetylated starch nanocrystals." Carbohydrate Polymers 80(4): 1078-1084.

Yang, J., F. Li, M. Li, S. Zhang, J. Liu, C. Liang, Q. Sun and L. Xiong (2017). "Fabrication and characterization of hollow starch nanoparticles by gelation process for drug delivery application." Carbohydrate Polymers 173: 223-232.

Zheng, H., F. Ai, P. R. Chang, J. Huang and A. Dufresne (2009). "Structure and properties of starch nanocrystal-reinforced soy protein plastics." Polymer Composites 30(4): 474-480.

Zhou, L., D. Fang, M. Wang, M. Li, Y. Li, N. Ji, L. Dai, H. Lu, L. Xiong and Q. Sun (2020). "Preparation and characterization of waxy maize starch nanocrystals with a high yield via dry-heated oxalic acid hydrolysis." Food Chemistry: 126479.

Zhu, F. (2017). "Encapsulation and delivery of food ingredients using starch based systems." Food chemistry 229: 542-552.

Zhu, J., L. Li, L. Chen and X. Li (2012). "Study on supramolecular structural changes of ultrasonic treated potato starch granules." Food Hydrocolloids 29(1): 116-122.

Zuo, Y. Y. J., P. Hébraud, Y. Hemar and M. Ashokkumar (2012). "Quantification of high-power ultrasound induced damage on potato starch granules using light microscopy." Ultrasonics Sonochemistry 19(3): 421-426. 